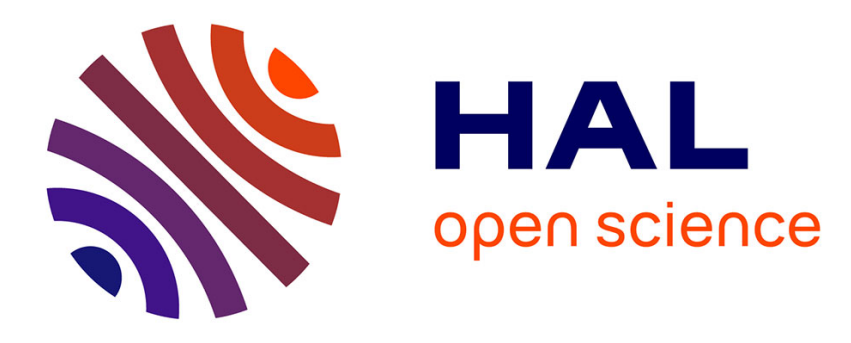

\title{
Mechanical effects of high power laser radiation on solid materials
}

Ch. Prat, J. Montagne, M. Autric

\section{To cite this version:}

Ch. Prat, J. Montagne, M. Autric. Mechanical effects of high power laser radiation on solid materials. Journal de Physique IV Proceedings, 1994, 04 (C4), pp.C4-107-C4-110. 10.1051/jp4:1994422 . jpa00252685

\section{HAL Id: jpa-00252685 https://hal.science/jpa-00252685}

Submitted on 1 Jan 1994

HAL is a multi-disciplinary open access archive for the deposit and dissemination of scientific research documents, whether they are published or not. The documents may come from teaching and research institutions in France or abroad, or from public or private research centers.
L'archive ouverte pluridisciplinaire HAL, est destinée au dépôt et à la diffusion de documents scientifiques de niveau recherche, publiés ou non, émanant des établissements d'enseignement et de recherche français ou étrangers, des laboratoires publics ou privés. 


\title{
Mechanical effects of high power laser radiation on solid materials
}

\author{
Ch. PRAT, J.E. MONTAGNE and M. AUTRIC \\ Institute of Fluid Mechanics - Laser - Matter Interaction Group, Parc Scientifique et Technologique de \\ Luminy, 163 avenue de Luminy, 13009 Marseille, France
}

I) Introduction During the first instants of the interaction, the optical properties of the material determine the energy fractions that it reflects and that penetrate it to a thickness generally defined by the optical penetration depth. The relative importance of specular reflexion and diffusion is then linked to the surface condition of the material.

Rough areas on the sample surface very rapidly release electrons and are the site at which changes of state occur. Heating of the material by the absorbed energy is accelerated by the changes in its thermal properties which inevitably occur when its temperature rises. Depending on the energy density used, melting and vaporization then affect the sample mass.

The vapor produced undergoes more or less complete ionization whose main mechanism is generally the multiphotonic effect and the inverse bremsstrahlung absorption.

Vaporization and plasma expansion transmit a fraction of the energy to the irradiated solid in the form of a shock wave and mechanical impulse.

A plasma therefore develops on the sample surface and spreads in the opposite direction to the radiation that created it, partially shielding the target. During the length of its existence the plasma absorbs, diffuses and if the critical electron density is reached, reflects the incident radiation; it also emits radiation in a large spectral range. In the ultra-violet region, this emission is particularly well absorbed by some materials and contributes to the surface heating and to vaporization and therefore to mechanical effects. This plasma could be initiate either in the jet of vaporized material or rather in the ambient gas surrounding the target. Thus the intensity threshold of plasma appearance could be drastically different with respect to the experimental conditions.

\section{II) Experimental set-up.}

The lasers These experiments were carried out using a $10.6 \mu \mathrm{m}$ TEA-CO 2 laser whose pulse is made up of a high-power peak of $80 \mathrm{~ns}$ FWHM, followed by a high-energy tail of 2.5 to $4 \mu \mathrm{s}$. Under these conditions, experiments could be carried out on a wide range of energy and average power densities ( 2 to $500 \mathrm{~J} / \mathrm{cm}^{2}$ and 1 to $200 \mathrm{MW} / \mathrm{cm}^{2}$ ).

Some experiments have been performed with a $\mathrm{KrF}$ laser. This laser delivers pulses of $400 \mathrm{~ns}$ duration with a maximum energy of about $200 \mathrm{~J}$ at $248 \mathrm{~nm}$.

For our experiments, the laser was configured with an $80-\mathrm{mm}$ diameter stable resonator which produced a pulse width of $300 \mathrm{~ns}$ and an output of $20 \mathrm{~J}$ on the target. The energy and power densities could be varied respectively from 3 to $130 \mathrm{~J} / \mathrm{cm}^{2}$ and 1 to 400 $\mathrm{MW} / \mathrm{cm}^{2}$ with good spot uniformity.

The surrounding gas was air with a pressure varying from $6 \times 10^{-3}$ to $10^{5} \mathrm{~Pa}$.

The material studied was an aluminum alloy AU4G (2017A) (Cu: 4.2\%; Al: 93\%; Fe; Zn; $\mathrm{Mg} ; \mathrm{Mn} ; \mathrm{Si}$ )

Pressure measurement set-up Most of the pressure measurements were carried out using piezoresistive carbon gauges. Some tests were however carried out on assemblies fitted with quartz and PVDF piezoelectric gauges 1

Mechanical coupling measurement set-up The target is fastened to the movable part of a pendulum, itself attached to a conductor coil which moves within the gap of a magnet, under the effects of the mechanical impulse hitting the test sample. When calibrated, the current produced in the coil provides an evaluation of the mechanical impulse. The mechanical coupling coefficient presented below, is the ratio of the measured mechanical impulse over the incident energy. 
III) Theoretical considerations The plasma jet created in front of the irradiated sample is now widely considered to expand in a one-dimensional flow up to a distance corresponding to the radius of the interaction spot, $R$. Thus the radial evolution is no longer negligible 2,3 (two dimensional flow).

According to Basov \& al. ${ }^{4}$, instant $t$ at which expansion evolves under conditions dominated by spherical expansion of the plasma now transparent is given by $: t=K_{0}^{-1 / 9} R^{8 / 9}$ $\emptyset^{-2 / 9}$ (s) [1] where $K_{0}=3.7 \times 10^{20} . Z^{3}(Z+1)^{3 / 2} \lambda^{2} A^{-7 / 2}$ (in MKSA units) ; $Z$ represents the degree of ionization, $A$ the atomic mass, $\lambda$ and $\emptyset$ are the wavelength and incident radiation power density.

Basov also proposed analytical expressions of the pressure and the mechanical impulse exerted on the target in the case of one-dimensional (respectively as a function of : $\left[\emptyset^{-3} \cdot \lambda . \tau^{0.5}\right]$ and $\left[\emptyset . \lambda . \tau^{0.5}\right], \tau$ :pulse duration) and two-dimensional flows (respectively as a function of : $\left[\varnothing^{-7} \cdot \lambda^{2} \cdot R\right]$ and $\left[\emptyset^{2} \cdot \lambda^{2} \cdot R\right]$.)

On the other hand, Dingus 5 "plasma energy balance model" can be used to calculate the trend of mechanical coupling coefficient. This model is based on the balance between the direct incident intensity that is absorbed and radiated by the plasma towards the sample and the intensity arriving at the target surface and contributing to the change of state, ionization and acceleration of a certain mass of material and to the heating of the rest of the sample. The calculation involves iteration on the ablated mass until the two expressions of intensity absorbed by the material become equal:

$\left(\alpha \varnothing_{\mathrm{o}}^{\prime}+\emptyset_{\mathrm{rad} .}\right)=\left(\varnothing_{\text {ion. }}+\varnothing_{\text {enth. }}+\varnothing_{\text {heat. }}+\varnothing_{\mathrm{acc} .}\right)[2]$ where $\varnothing_{\mathrm{o}}^{\prime}$ is the incident intensity not absorbed by the plasma; $\alpha$ is the absorptivity on the target surface; $\emptyset_{\text {rad. is the intensity }}$ radiated by the plasma; $\varnothing_{\text {ion. }}$ is the intensity contributing to ionization; $\varnothing_{\text {enth. }}$ is the intensity contributing to change of state; $\varnothing_{\text {heat. }}$ is the intensity conducted into the rest of the sample; $\emptyset_{\text {acc. }}$ is the intensity contributing to the propulsion of ejected matter.

IV) Results and discussion In vacuum, the threshold of the different processes occuring during the laser-matter interaction, depend mainly on the optical properties of the irradiated material with respect to the incident radiation. It is well known now that the absorptivity of metal is greater in the UV field than in the visible or IR range of wavelength. In addition, the energy of the photons is about 50 times greater for a $248 \mathrm{~nm}$ radiation than for a $10.6 \mu \mathrm{m}$ one. Then, as could be seen in fig.1A-1B, a greater mechanical effect could be induced on Al. alloy, with lower intensities using a UV laser radiation than a IR one. Because of the initial roughness and oxide on the surface of the sample, the mechanical effect could be induced at intensities lower for the first shots than for the following. After a few shots or at great intensity, the surface is cleaned and the mechanical coupling coefficient tends to be constant at given intensity (fig.1B)

For a $10.6 \mu \mathrm{m}$ radiation, significant mechanical effects could be noted from 6 $\mathrm{MW} / \mathrm{cm}^{2}$. Because of the growing plasma opacity and the change of state of some material, the mechanical coupling evolution slows down and reaches a constant value (namely $\approx 2$ dyne.s/J) from 30 to $200 \mathrm{MW} / \mathrm{cm}^{2}$. No such significant influence of the number of pulses could be observed, due mainly to the pulse duration which is much greater than the UV one. As can be seen in fig. 1A-1B, the Dingus model (curved lines) describes the transition period between the rapid increase of the mechanical coupling coefficient and its levelling off, as the Basov calculation (straight lines) only provides the trend after the appearance of a optically thick plasma. According to expression [1] the flow is supposed to be 1D at $\lambda=248 \mathrm{~nm}$ and $2 \mathrm{D}$ at $\lambda=10.6 \mu \mathrm{m}$. 


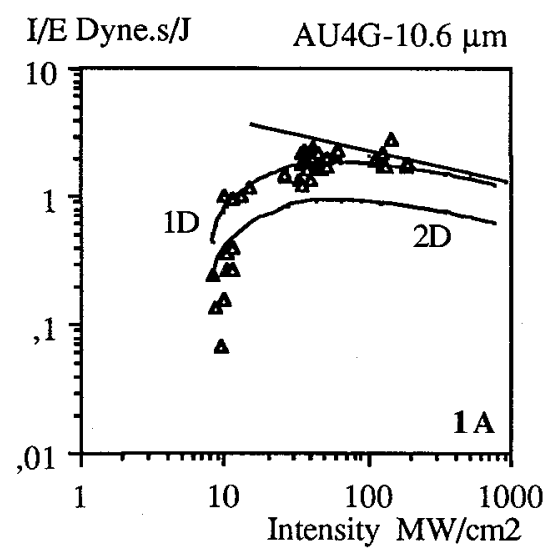

Basov model : spot radius : $\mathrm{R}=0.35 \mathrm{~cm}$ ionization degree : $\mathrm{Z}=3$

Dingus model : pulse duration : $3 \mu \mathrm{s}$;

Al. alloy absorptivity : 0.4 (cf ref. 6 )
I/E Dyne.s/J AU4G-248 nm

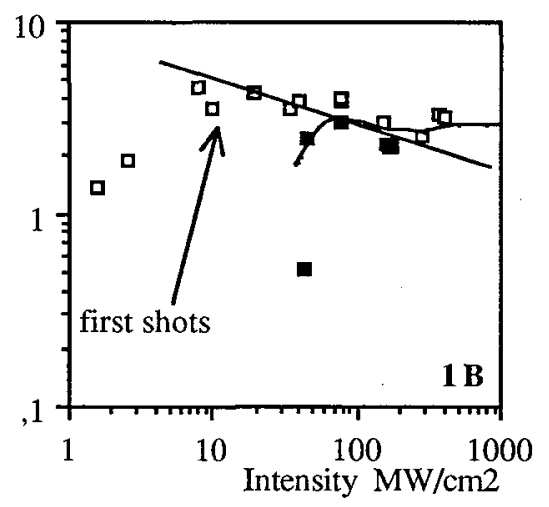

Basov model : pulse duration : $300 \mathrm{~ns}$ ionization degree $: Z=3$

Dingus model : pulse duration : $300 \mathrm{~ns}$ Al. alloy absorptivity : 0,5

Fig.1A-1B : Mechanical coupling coefficient versus average intensity. Experimental and theoretical results. Ambient pressure : $6 \times 10^{-3} \mathrm{~Pa}$.

As the irradiation is performed in air, the plasma plume grows into different kinds of hydrodynamic regimes (Laser Supported Combustion Wave and Laser Supported Detonation Wave respectively for an ambient pressure of about $10^{3}$ to $5 \times 10^{4} \mathrm{~Pa}$ and $5 \times 10^{4}$ to $10^{5} \mathrm{~Pa}$ ). These consist mainly of an absorption front moving away from the surface during the pulse duration and that way protecting it, inducing a drop in the mechanical coupling coefficient and in the amplitude of the shock undergone by the sample (fig. $2 \mathrm{~A}$ ).

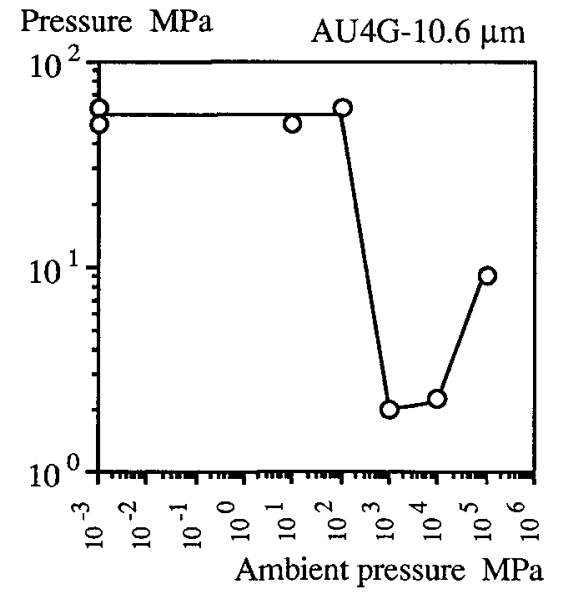

Fig. 2A : Shock wave amplitude versus ambient pressure.

Laser intensity : $190 \mathrm{MW} / \mathrm{cm}^{2}$.

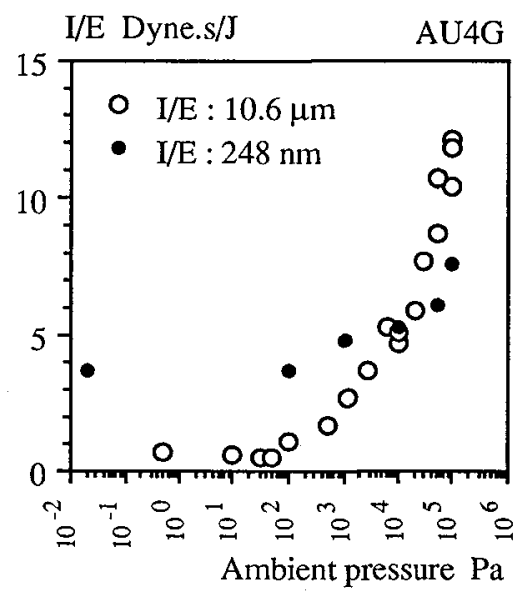

Fig. 2B : Mechanical coupling coeffiecient versus ambient pressure.

Laser intensity : $\lambda=10.6 \mu \mathrm{m}: 5 \mathrm{MW} / \mathrm{cm}^{2}$

$$
\lambda=248 \mathrm{~nm}: 95 \mathrm{MW} / \mathrm{cm}^{2} \text {. }
$$


Inspite of this shielding process of the plasma, the shocked gas within the surface and the absorption wave induces mechanical effects on the sample. If the incident intensity is low enough to avoid the ignition of an optically thick plasma, the mechanical impulse is edging up (see fig. 2B) with the increasing ambient pressure. In fact an optically thin plasma is also created, but its expansion is prevented by the ambient gas resulting in an "piston effect" on the sample.

The results of pressure measurements presented below in fig.3A-3B, show the amplitude of the peak of the pressure signal to which it is possible to match a power density value read at the laser pulse, as long as the shape of the laser pulse and the pressure signals are quite similar. According to the expression [1] the flow remains one-dimensional during the length of the laser pulse peak ( $80 \mathrm{~ns}$ ) for the $10.6 \mu \mathrm{m}$ laser pulse and during the whole pulse duration ( $\approx 300 \mathrm{~ns}$ ) at $248 \mathrm{~nm}$. These results are compared with those obtained by Mc Mordie et al. ${ }^{7}$ on a $0.66 \mathrm{~mm}$-thick DTD-5104 Al alloy target, using quartz gauges for various rise time of the laser pulse peak. For the longest time $(43 \mathrm{~ns})$, the measurements prove to be in good agreements with ours. The Basov theory seems to describe well the experimental trend for intensities greater than $10 \mathrm{MW} / \mathrm{cm}^{2}$. Indeed, the plasma created at lower intensities does correspond to the optically thick one considered in this model. All these results were obtained in vacuum $\left(6 \times 10^{-3} \mathrm{~Pa}\right)$.

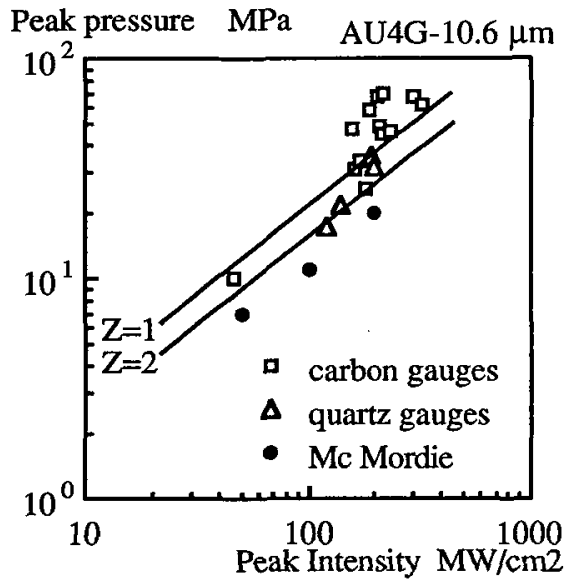

Fig. 3A : Theoretical and experimental Fig. 3B : Theoretical and experimental pressure results. Target thickness : $1.5 \mathrm{~mm}$ (except McMordie's data)

\section{References}

1) Ch. Prat, J.E. Montagne et al."High power laser radiation induced shock waves in solids." 19 th International Symposium on Shock Waves, Book of abstracts p.312, vol. I,Marseille, 26-30 Juillet 1993.

2) C.R. Phipps, T.P. Turner, R.F. Harrisson, G.W. York, W.Z. Osborne, G.K. Anderson, X.F. Corlis, L.C. Haynes, H.S. Steele, K.C. Spicochi. "Impulse coupling to targets in vacuum by $\mathrm{KrF}, \mathrm{HF}$ and $\mathrm{CO}_{2}$ single pulse lasers", J.Appl.Phys. 64 (3),1988

3) H. Puell "Heating of laser produced plasmas generated at plane solid targets (I. Theory)", Z. Naturforsch $25 a$, (1807-1815), Sept. 1970

4) N.G. Basov, V.A. Gribkov, O.N. Krokhin, G.V. Sklizkov, "High temperature effects of intense laser emission focused on a solid target", Soviet Physics, J.E.T.P., Vol. $27 n^{\circ} 4$, Oct. 1968

5) R.S. Dingus, S.M. Goldman."Plasma energy balance model for optical-laser induced impulse in vacu", Proc. of the International Conference on Lasers, 1986, pp.111-122.

6) Ch. Prat, G. Inglesakis, M. Autric. "Pulsed $\mathrm{CO}_{2}$ laser-material interaction; thermomechanical effects." SPIE Vol. 1810, pp. 590-593, 1993.

7) J.A. Mc Mordie, P.D. Roberts. "The interaction of pulsed $\mathrm{CO}_{2}$ laser radiation with aluminium"; J.Phys.D: Appl.Phys. vol 8, 1975 